\title{
SYNOPSES
}

\section{STATISTICAL METHODS FOR ACTUARIES}

\author{
By Patrick Carroll
}

(Synopsis of a paper presented to the Society on 7 January 1986)

Statistical Methods are central to actuarial investigation. This emphasis has increased with the move away from a primary concern with life and pension matters, where the focus is on deterministic models. The increasing pressure on available space in the professional examination syllabus means that it is important that an appropriate selection is made from the available statistical methodology. Unfortunately actuarial problems are characterized by skewed distributions, correlated errors, situations which call for multiplicative rather than additive models, and a host of other 'non-standard' features. The paper comprises a wide ranging review of modern statistical methodology and an appraisal of the value of each method for actuarial investigations.

An extension of the basic techniques already central to actuarial training is advocated. In particular the summary and display of data including multivariate data, the use of data transformations, distribution-free (non-parametric) inference, the use of a wider range of distributions, in particular the 'stable-law' family, and a greater appreciation of the secondary use of data from government and market research sources. All this is possible with only a limited extension of the calculus and algebra requirements for students and by exploiting modern computing resources.

The paper then deals in detail with the major subject areas which should be considered part of professional or post-qualifying training.

Multivariate methods have 'come alive' by virtue of computing power. No other body concerned with large data bases has ignored them. The uses of multiple regression, principal components, factor analysis, cluster analysis, multi-dimensional scaling, correspondence analysis, canonical variate analysis and discriminant function analysis are outlined. Examples of the use of each technique are described.

Survival analysis has developed with increasing rapidity since Cox's 1972 paper on Regression Models and Life Tables. The principles of survival analysis are entirely consistent with traditional actuarial methods. The straightforward methods of estimating survival distributions for individual level data and the non-parametric testing of hypotheses are ideally suited to the examination syllabus. The full Cox model with its estimation difficulties is described in detail. An appreciation of these methods is essential for the preparation of life underwriting manuals using the recent literature in medical statistics. The whole 
subject is an important component of post-graduate and/or post-qualifying training.

Traditionally smoothing formulae have only been used for graduation. An extension of such techniques leads to the modelling and forecasting of Time Series. The actuarial literature of recent years abounds with examples of the use of Box-Jenkins models, particularly for investment problems. The presence of elementary time series modelling in the statistics syllabus and its use in research in one area suggests that it is an important subject for more detailed examination coverage, and possibly fruitful as a research method in other areas, particularly general insurance.

The development of Generalized Linear Models and their estimation using the GLIM software package is described. Several examples of the use of these models in general and life insurance are given. The subject is seen as an essential part of post-examination training. However the key approaches to GLIM modelling, e.g. the use of log transformations, likelihood ratio testing, etc., could be introduced into the current examination without major disruption.

Bayesian Inference has been neglected by the majority of actuaries. The development and use of Credibility or Experience Rating in North America and Continental Europe has shown that Empirical Bayes Methods can provide a productive approach to problems in Risk Theory. Unfortunately the mathematical sophistication required for a full treatment of the topic makes it unsuitable as a major component of examinations and probably only accessible to a limited number of actuaries in a post-qualifying course.

The paper concludes with an extensive bibliographic note, which provides a guide to the more recent texts in all subject areas. Some papers which give examples of the use of the new techniques in actuarial research are also cited.

\section{PARTNERSHIP PENSION ARRANGEMENTS}

\section{By Geoffrey Bernstein}

(Synopsis of a paper presented to the Society on 21 January 1986)

THIS paper outlines some of the recent developments in the field of planning partnership pensions. The word 'partner' refers to one of a group of people working together in an unincorporated body. They are taxed as 'self-employed'. The legislation governing their pension provision is quite different from that of employees taxed under Schedule E. The paper focuses particularly on selfinvested funds available through insurance companies or through a "captive or private' friendly society.

Pension planning is an integral part of overall partnership planning which includes: 